\title{
Arctic sea ice freeboard from IceBridge acquisitions in 2009: Estimates and comparisons with ICESat
}

\author{
R. Kwok, ${ }^{1}$ G. F. Cunningham, ${ }^{1}$ S. S. Manizade, ${ }^{2}$ and W. B. Krabill ${ }^{3}$ \\ Received 3 October 2011; revised 6 December 2011; accepted 6 December 2011; published 9 February 2012.
}

[1] During the spring of 2009, the Airborne Topographic Mapper (ATM) system on the IceBridge mission acquired cross-basin surveys of surface elevations of Arctic sea ice. In this paper, the total freeboard derived from four $\sim 2000 \mathrm{~km}$ transects are examined and compared with those from the 2009 ICESat campaign. Total freeboard, the sum of the snow and ice freeboards, is the elevation of the air-snow interface above the local sea surface. Prior to freeboard retrieval, signal dependent range biases are corrected. With data from a near co-incident outbound and return track on 21 April, we show that our estimates of the freeboard are repeatable to within $\sim 4 \mathrm{~cm}$ but dependent locally on the density and quality of sea surface references. Overall difference between the ATM and ICESat freeboards for the four transects is $0.7(8.5) \mathrm{cm}$ (quantity in bracket is standard deviation), with a correlation of 0.78 between the data sets of one hundred seventy-eight $50 \mathrm{~km}$ averages. This establishes a level of confidence in the use of ATM freeboards to provide regional samplings that are consistent with ICESat. In early April, mean freeboards are $41 \mathrm{~cm}$ and $55 \mathrm{~cm}$ over first year and multiyear sea ice (MYI), respectively. Regionally, the lowest mean ice freeboard $(28 \mathrm{~cm})$ is seen on 5 April where the flight track sampled the large expanse of seasonal ice in the western Arctic. The highest mean freeboard $(71 \mathrm{~cm})$ is seen in the multiyear ice just west of Ellesmere Island from 21 April. The relatively large unmodeled variability of the residual sea surface resolved by ATM elevations is discussed.

Citation: Kwok, R., G. F. Cunningham, S. S. Manizade, and W. B. Krabill (2012), Arctic sea ice freeboard from IceBridge acquisitions in 2009: Estimates and comparisons with ICESat, J. Geophys. Res., 117, C02018, doi:10.1029/2011JC007654.

\section{Introduction}

[2] With the rapid decline in the thickness of the Arctic Ocean sea ice cover seen in altimetry data [Giles et al., 2007; Kwok et al., 2009], Operation IceBridge (OIB) was implemented as an airborne remote sensing program to extend the laser altimeter time series through the gap between the end of ICESat data collection in 2009 and the launch of the ICESat-2 lidar in 2016. The primary goal is to minimize the impact of the interruption of the lidar time series established by ICESat for monitoring changes in the polar sea ice covers and ice sheets. The ATM system, developed at NASA Wallops Flight Facility, is currently the primary lidar instrument employed by OIB to provide this surface elevation time series, with the expressed objective of producing routine estimates of sea ice freeboard and thickness for scientific use.

\footnotetext{
${ }^{1}$ Jet Propulsion Laboratory, California Institute of Technology, Pasadena, California, USA.

${ }^{2}$ URS Corporation, NASA Wallops Flight Facility, Wallops Island, Virginia, USA.

${ }^{3}$ Laboratory for Hydrospheric Processes, NASA Goddard Space Flight Center, Wallops Island, Virginia, USA.

Copyright 2012 by the American Geophysical Union. 0148-0227/12/2011JC007654
}

[3] The ATM system has provided surveys of Greenland nearly every year since 1993 [Krabill et al., 2002] and these repeated surveys have produced some remarkable results on the thinning of the Greenland ice sheet [e.g., Krabill et al., 2000; Krabill et al., 2004]. Comparatively, previous surveys of the Arctic sea ice cover have been restricted to short campaigns for exploring remote sensing techniques or validation of satellite missions, but not intended for developing a usable time series. Giles et al. [2007] provided the first analysis of coincident lidar (from the ATM system) and radar altimetry data over sea ice, and demonstrated the potential of combining radar and lidar data to estimate snow depth. Kurtz et al. [2008] compared surface elevation and roughness measurements from the ATM system with those from ICESat over the sea ice cover north of Alaska taken during March 2006. In particular, they found that when leads that are larger than the ICESat footprint are present, the ICESat-and ATM-derived freeboards are found to agree to within $2 \mathrm{~cm}$. Likewise, Connor et al. [2009] found consistent elevations of open leads in ATM data and those from the radar altimeter on the Envisat platform. These investigations have highlighted the quality and usefulness of the ATM data over sea ice. However, the large-scale operational uses of the ATM lidar as an instrument for monitoring changes in the sea ice cover have yet to be demonstrated. Analysis of 
the cross-basin elevation surveys acquired by the ATM system is the subject of this paper.

[4] The first Arctic deployment of the OIB airborne assets was in March and April of 2009. Data from four OIB flight lines, each covering $\sim 2000 \mathrm{~km}$ in distance, are used in our analysis (Figure 1). These long transects were selected to provide a broad sampling of the snow and ice prior to the expected onset of melt over the Arctic sea ice cover. They were flown on 31 March, 2 April, 5 April, and 21 April. Based at the Thule airbase, the earliest flight sampled the ice cover of the Lincoln Sea, north of the Greenland Coast, and the Fram Strait. The next flight, from Thule to Fairbanks, sampled the edge of the tongue of mixed multiyear/first year sea ice west of the Canadian Arctic Archipelago. The return flight (5 April) flew north to $86^{\circ} \mathrm{N}$, acquiring data over the large expanse of seasonal ice in the Beaufort Sea before turning east and collecting data over a patch of multiyear sea ice (MYI) and finally crossing the Greenland coast. The fourth flight (21 April), an outbound and return along the same track provided a useful data set to test the consistency of retrieval techniques. In all, these flights represent extensive trans-Arctic airborne surveys of the surface elevation of Arctic sea ice. All OIB flight lines have been designed, within the limits of the airborne platform and airspace restrictions, to sample the gradient in ice thickness across the Arctic Ocean. Some of these flight lines will be repeated annually throughout OIB.

[5] The paper is organized as follows. Section 2 describes the instruments and the data sets used in our analysis. In section 3, the following topics are addressed: (1) the calibration of the ATM elevations; (2) identification of sea surface elevations for freeboard determination; and (3) the estimation of sea surface height along track using a limited number of sea surface references. As well, we use the repeat track on 21 April to illustrate our methodology and the quality of the retrieved freeboard and sea surface. The results from the four surveys and their comparisons with ICESat are summarized in section 4 . The regional distribution of the freeboard and their comparisons to ICESat are provided. Summary remarks and conclusions are provided in the last section.

\section{Data Description}

[6] The data sets from Operation IceBridge (OIB) are archived and available at the National Snow and Ice Data Center (NSIDC). Of the suite of OIB instruments, the Airborne Topographic Mapper (ATM) that has been employed to provide high-precision altimetry of the Arctic sea ice cover is the subject of this paper. In this section, we describe the ATM lidar and other data sets used in our analysis.

\subsection{ATM Lidar}

[7] The ATM is a conical-scanning laser ranging system operated at a wavelength of $532 \mathrm{~nm}$ with a pulse repetition frequency of $5 \mathrm{kHz}$ and a scan rate of $20 \mathrm{~Hz}$; the off-nadir scan angle is $15^{\circ}$ [Krabill et al., 2002]. To provide accurate elevation estimates, the instrument includes a differential GPS system for accurate positioning of the aircraft, and inertial sensors (accelerometers and gyroscopes) for precise attitude determination. With nominal OIB flight parameters (i.e., operating altitude and ground speed: $500 \mathrm{~m}$ and $250 \mathrm{kts}$ ), the ATM observation geometry provides an across-track scan swath of $\sim 250 \mathrm{~m}$. Near the center of the swath, the spacing between neighborhood laser footprints, of $\sim 1 \mathrm{~m}$ in diameter, is approximately $3-4 \mathrm{~m}$ in the along-and acrosstrack directions. The sample density is higher (submeter) near the edges of the swath due to the conical scanning geometry of the system.

[8] Generally, the backscatter from a snow or ice surface within the beam of the ATM is sufficient for measurement of the time delay of a return signal and for determination of the total propagation distance. However, the presence of extremely smooth surfaces along the flight path results in some measurement dropouts, probably due to the specular reflection of the ATM beam. In the processing of the data, the travel time data are combined with GPS navigation measurements and aircraft orientation parameters to derive surface elevation measurements relative to the WGS84 reference ellipsoid. Typical elevation accuracy is better than $10 \mathrm{~cm}$ [Krabill et al., 2002]. When the received signal strength is low, there are expected biases that need to be corrected; this is discussed in section 3. In terms of granularity, ATM elevations are provided in data files that cover tracks of $\sim 35 \mathrm{~km}$ in length, each containing over a million elevation estimates.

[9] Aerial photographs along the ATM swaths are also captured to assist in the classification of surface types sampled by the lidar. These digital camera (CAMBOT) pictures are used here to assist in the identification of open water and lead samples in the ATM samples.

\subsection{ICESat Freeboard Estimates}

[10] A composite field of gridded ICESat freeboards (smoothed with a $50 \mathrm{~km}$ diameter Gaussian kernel) from the winter campaign in 2009 (9 March through 11 April) is used here. Freeboards are derived using the procedures described by Kwok et al. [2007] and Kwok and Cunningham [2008]. These are the same procedures used to produce the sea ice freeboard and thickness estimates reported by Kwok et al. [2009]. It is worth noting that, in order to compensate for sea surface biases due to partial lead/sea surface coverage within an ICESat footprint, the freeboard elevations have been adjusted using the apparent reflectivity of the return signal. The reader is referred to the above papers for more detailed descriptions and assessments of the ICESat estimates.

\subsection{Other Data Sets}

[11] Basin-scale estimates of MYI coverage from April of 2009 are from analysis of QuikSCAT data (see Figure 1). Estimation and assessment of the spatial distribution of MYI coverage from scatterometer fields are described in the work of Kwok [2004]. This data set is used primarily to understand the variability of freeboard over the two dominant ice types in the Arctic Ocean. The EGM2008 geoid is used in our estimation of sea surface elevation.

\section{Data Analysis}

[12] This section is divided into four parts. First, we discuss the calibration of the lidar elevations. Second, our approach to identify open water and thin ice samples in the ATM data is discussed. Third, we describe how the available sea surface samples are used to estimate the sea surface 


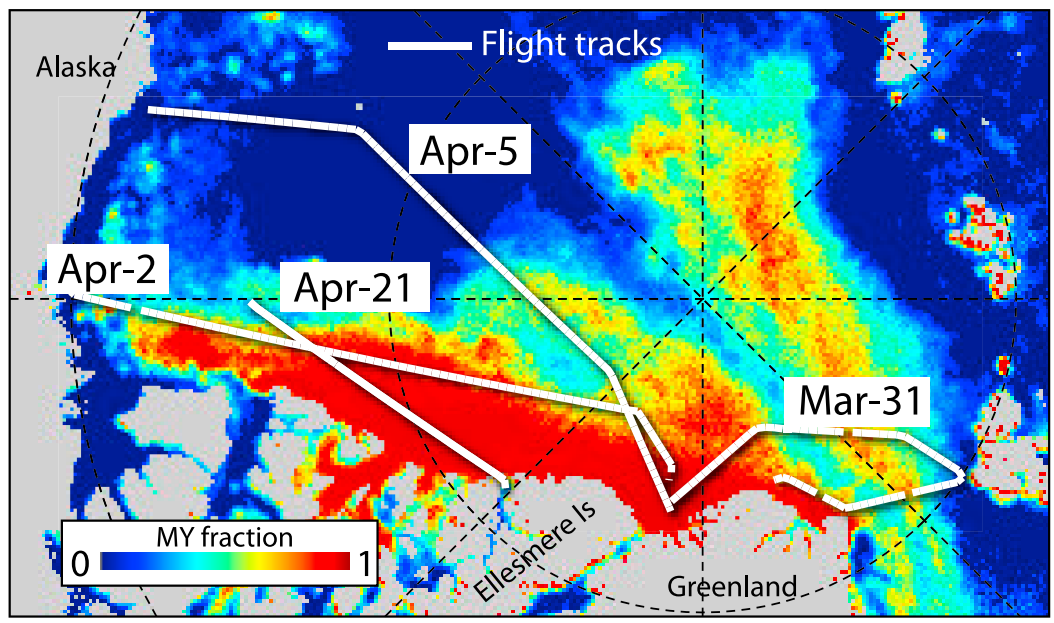

Figure 1. Tracks of four IceBridge flights (white) in spring of 2009 over a map of multiyear sea ice coverage from QuikSCAT. ATM lidar data acquired during these flights, each $\sim 2000 \mathrm{~km}$ in length, are analyzed in this paper. Dates flown are shown next to each track.

profile and freeboard along the four ATM tracks. Last, we use the repeat track on 21 April to illustrate our methodology and the quality of the retrieved freeboard and sea surface estimates.

[13] Before we proceed, a brief note regarding terminology and the adjustments we have made to all elevation data. Freeboard, as used here, refers to the elevation of the airsnow interface from the local sea surface. For the Arctic sea ice cover, this freeboard consists generally of a snow layer superimposed on the freeboard of floating sea ice. This total freeboard height, $h_{f}$, above the sea surface can be written as the sum of two terms:

$$
h_{f}=h_{f s}+h_{f i},
$$

where $h_{f s}$ and $h_{f i}$ are the thicknesses of the snow and ice layers above the sea surface.

[14] The freeboard, $h_{f}$, is the difference between surface elevation, $h_{o b s}$, as measured by a laser altimeter (i.e., assuming no returns from the snow volume) and the local sea surface height, $h_{s s h}$ :

$$
h_{f}\left(x, t_{i}\right)=h_{o b s}\left(x, t_{i}\right)-h_{s s h}\left(x, t_{i}\right) .
$$

These parameters vary in space $(x)$ and time $(t)$.

[15] Since centimeter-level knowledge of the time-variable sea surface height is not available, a necessary step in retrieving freeboard is the identification of accurate sea surface references $\left(h_{s s h}\right)$ over the ice cover. Some of the many practical and altimeter dependent issues associated with the identification of sea surface samples have been discussed in the work of Kwok [2011].

[16] Prior to our analysis, we remove the following contributions to the ATM elevations: geoidal undulations (EGM2008), ocean tides, inverted barometer effects, and signal strength corrections described in section 3.1. This has the effect of reducing the along track variability of the observed elevations. Of the three terms, the spatial variability of the geoid is the most energetic at all length scales and, as seen here, its residuals still dominate the variability in the estimated sea surface height. After the removal of these known contributions to sea surface variability, the residual variations of the sea surface - as seen in the results in the latter part of this section and in section 4-is on the order of $\sim 0.5 \mathrm{~m}$.

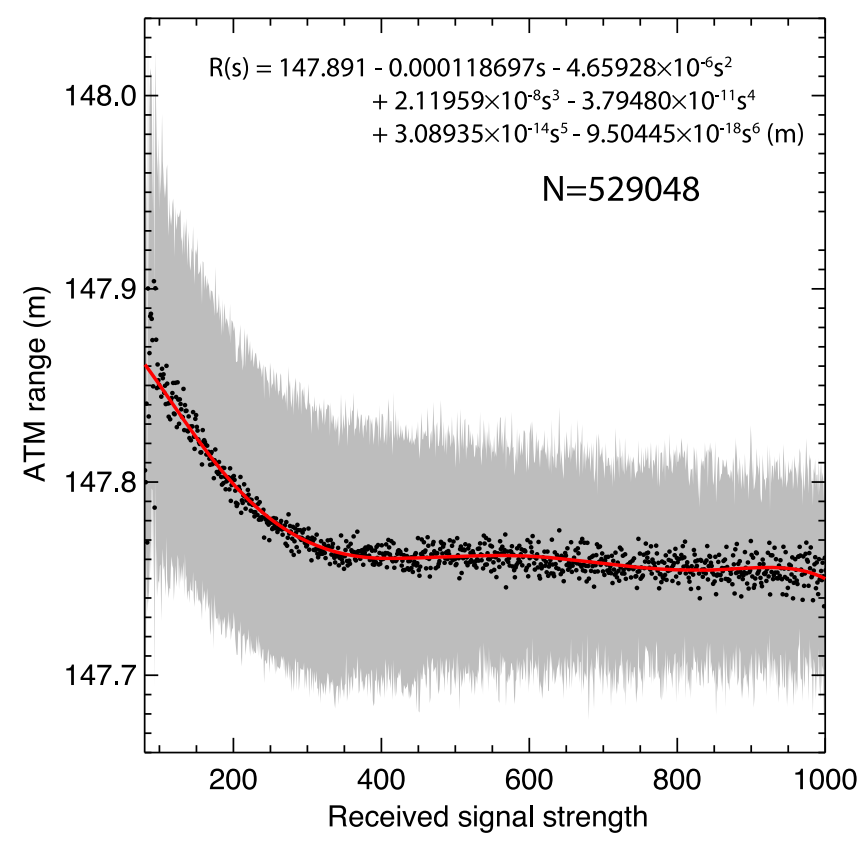

Figure 2. Dependence of measured range on received signal strength for the 2009 ATM instrument. To obtain these results, the transmitted pulse strength is held constant while an attenuator in the optical path varies the received signal strength to levels expected during flight. Changing the transmitted signal strength within the range of levels encountered in flight does not change the results shown here. Polynomial fit (and their coefficients) to the calibration data is shown in red on the plot. Black dots and gray error bars are the mean and standard deviation of the measured range for each unit of signal strength. 

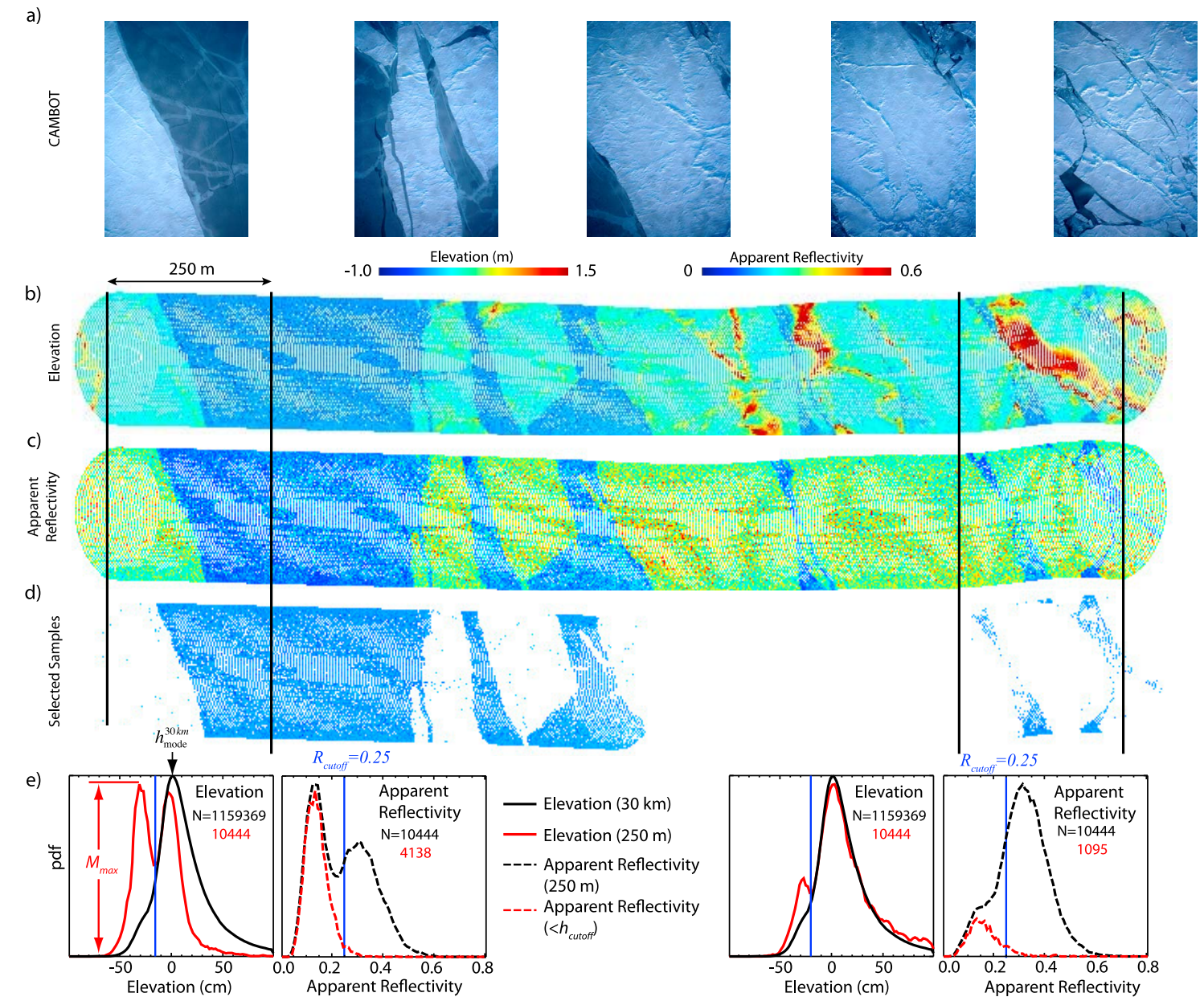

Apparent Reflectivity

Figure 3. Ice/water discrimination in ATM data. A $2 \mathrm{~km}$ segment of: (a) CAMBOT imagery of sea ice; (b) color-coded ATM elevation samples (swath width of the lidar is $\sim 200 \mathrm{~m}$ ); (c) corresponding received apparent reflectivity; and (d) selected sea surface samples (in blue). To discriminate between sea ice and open water/thin ice, our procedure (described in the text) examines the elevation and apparent reflectivity of the sample population along each $250 \mathrm{~m}$ track segment. (e) shows the distributions from two segments where sea surface samples are identified. Ocean tides, geoid, and inverted barometer effects have been removed from the ATM elevations.

\subsection{Calibration of ATM Elevations}

[17] The ATM measures the vector distance from the aircraft to the terrain below. The vector direction is determined by the aircraft attitude and pointing angle of the ATM scanning mirror. Its magnitude, or range, is the speed of light multiplied by the time delay between the downward transmission of a laser pulse and the detection through a telescope of the backscatter from the terrain below. Electrical and optical delays within the ATM give rise to biases between the true range and computed range. For the OIB flights, these range biases are measured using a calibration procedure on the ground for subsequent application to the flight data during postflight processing. In the calibration process, an external mirror redirects the laser/telescope horizontally to a flat target, at a distance of 150-200 m, while an optical attenuator continuously varies the strength of the received signal. The bias estimate is the ATM range minus a reference range provided by an independent, calibrated surveygrade distance measurement device (the accuracy of this device is better than $1 \mathrm{~cm}$ at distances of less than $1000 \mathrm{~m}$ ). The bulk of the range bias is due to fixed internal delays, but some variation related to signal amplitude arises from the waveform processing of received pulses. Figure 2 shows the calibration results for the 2009 ATM instrument. The variations may be unimportant over bright snow covered ground but must be considered over open-water leads, from which the backscatter signal tends to be weak. It is the determination of the range to these low-backscatter targets that is the subject of this subsection.

[18] Within each ranging period, the ATM system records the transmitted waveform as well as the received waveform. To compute the range to the surface, the time delay $\left(t_{d}=t_{r}-t_{o}\right)$ between the location of the leading edge of the transmitted pulse $\left(t_{o}\right)$ and the location of the leading edge $\left(t_{r}\right)$ of the received waveform, at $75 \%$ of the peak, is used. This $75 \%$ value is a compromise between two factors: tracking a steep portion of the pulse and remaining above the background noise. This level is somewhat arbitrary because 

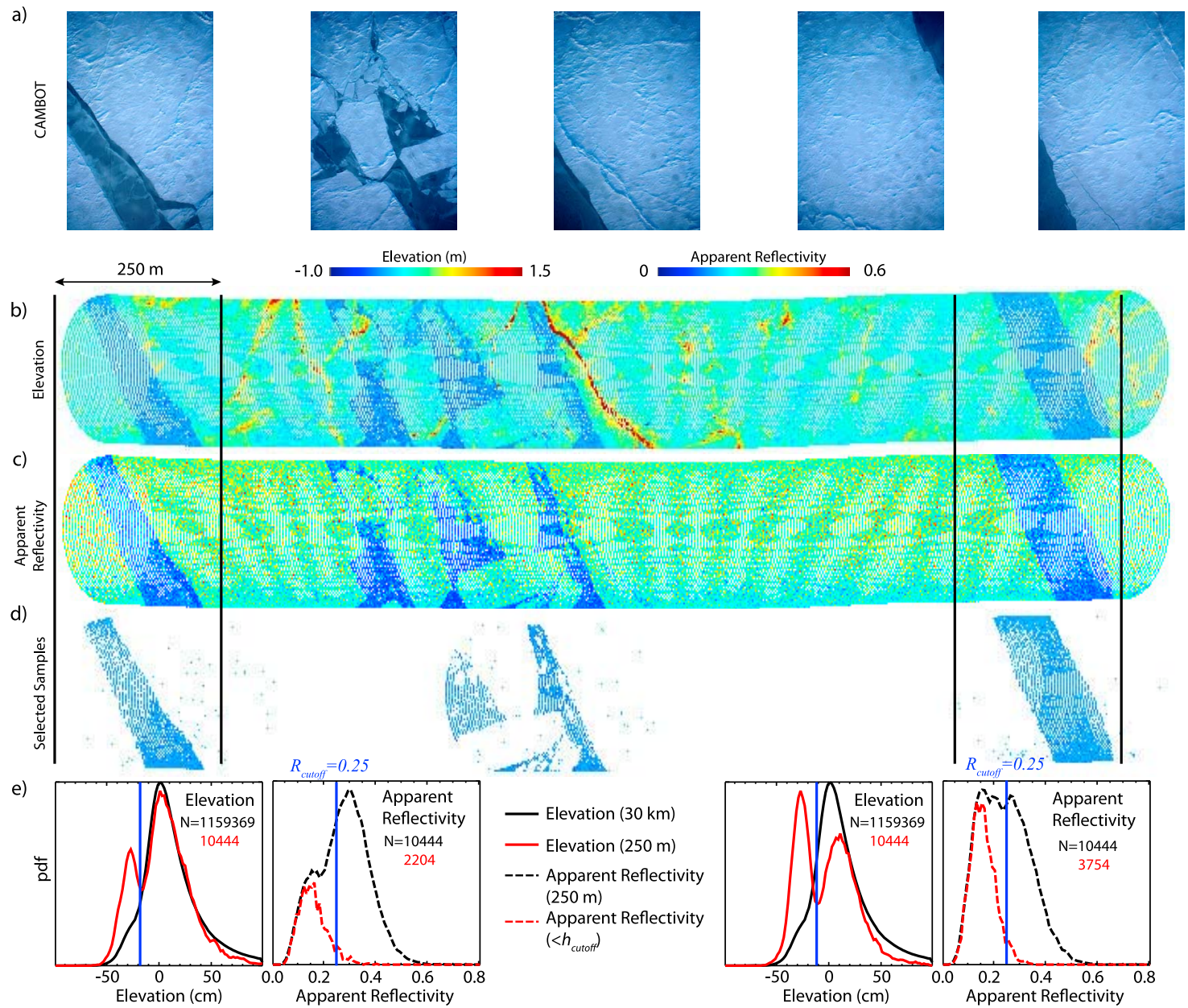

Figure 4. Another $2 \mathrm{~km}$ ATM segment where sea surface samples are found. For description, see caption in Figure 3.

the leading edge is steep when the signal strength is high. A leading-edge technique is used rather than a centroid or pulse fitting technique because there had been some history of corrupted trailing edge pulses. Although the problem is gone, the method is still used consistently for these data sets.

[19] Since the elevation is derived using the leading edge of the waveform, the estimated range is surface reflectivity or signal strength dependent. That is, when the return energy is low (or the signal-to-noise ratio is reduced), the estimated range is displaced toward the peak of the return waveform. The consequence is increased range to the surface leading to lower surface elevations. This effect is readily apparent in the range versus signal strength plot in Figure 2. Between a signal level of 100 and 300 , there is a nearly a $10 \mathrm{~cm}$ increase in the range bias to the reference surface. Thus, this potential source of error in determining the range to lowreflectance sea surfaces is significant and causes overestimations in freeboard. To compensate for the expected biases, we fitted a polynomial (shown in Figure 2) to the calibration data to estimate the expected signal-dependent biases. Corrections are applied to individual ATM elevations based on their signal strength; these adjustments are referenced to the average range at signal strengths between 900 and 1000 in Figure 2. We show in the following sections the effects of these corrections on the derived freeboard. Henceforth, unless otherwise noted, all ATM elevations $\left(h_{A T M}\right)$ used in this analysis include this correction.

\subsection{Identification of Sea Surface Samples}

[20] We find the apparent reflectivity of the surface returns together with low elevations to be effective indicators of whether open water or thin ice is contained within an ATM footprint. Apparent reflectivity $(R)$ is defined as the ratio of the reflected laser signal strength to the transmitted pulse signal strength; both quantities are reported for each laser shot. Figures $3 a-3 c$ and Figures $4 a-4 c$ illustrate this: the fields show clear correspondence between the low-intensity samples in the CAMBOT imagery, and ATM samples of low elevation and low $R$. Low-intensity CAMBOT samples are characteristic of thin bare-ice surfaces that have albedos close to that expected of smooth open water. Crucially, the contrast between ice and open water/thin ice seen in the CAMBOT image is also evident in the spatial pattern of $R$ in the ATM data Figures 3a, 3c, 4a, and 4c. This suggests that both the CAMBOT and $R$ data can be utilized to identify near sea surface samples (i.e., thin ice/open water)..

[21] In our approach, we use only $R$ for open water/thin ice detection because the CAMBOT camera is not instrumented to provide the necessary timing and orientation information 


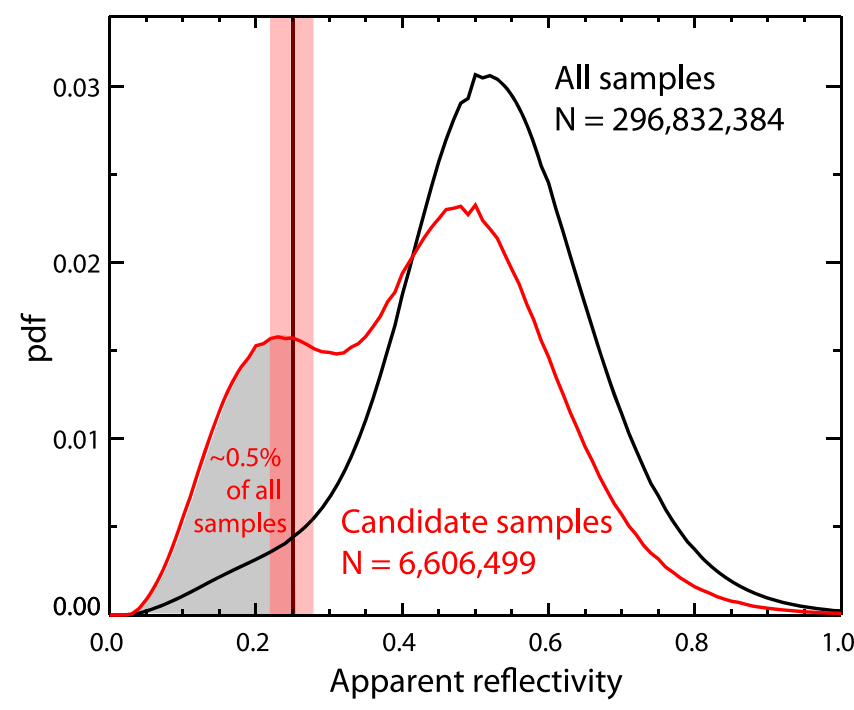

Figure 5. Apparent reflectivity. Distribution of all ATM samples from the four tracks (black). Bimodal distribution of the low-elevation samples (red) identified using the procedure based on elevation alone (see section 3 ). The population of low-elevation samples selected as sea surface tiepoints. Black vertical line shows the $R_{\text {cutoff }}$ at 0.25 and the red band shows the range between 0.225 and 0.275 (discussed in the text).

for accurate geometric co-registration with the ATM elevation samples. Furthermore, as seen in Figures 3 and 4, the CAMBOT data (in the 2009 campaign) do not provide uninterrupted coverage of the ATM swath; the CAMBOT imagery has been intended to serve as visual aids in the interpretation of the surface type sampled by the ATM swath, and not to provide cartographic quality imagery. Hence, the CAMBOT data is only used to validate the use of $R$ for detection of near sea surface samples. We note that in certain OIB campaigns, an airborne digital camera (Digital Mapping System-DMS) also acquires high-resolution (submeter) panchromatic imagery for the purpose of integrated ATM-DMS analysis for ice/water discrimination. This capability, useful for providing added sensitivity to the detection process, was not available during the 2009 Arctic campaign.

[22] Of the four 2009 sea ice tracks examined, we find the levels of $R$ to be surprisingly stable and consistent when the ATM is operated within the nominal OIB flight parameters (i.e., operating altitude and ground speed: $\sim 500 \mathrm{~m}$ and $250 \mathrm{kts})$. If the operating altitude deviates from nominal, the levels of $R$ do change as the distance to the surface changes. In fact, when the ATM was operated at an altitude of $760 \mathrm{~m}$ in one of the segments of the four OIB tracks examined here, the levels of $R$ decreased correspondingly. To compensate for this effect in our detection scheme, the $R$ thresholds used in our procedure (described next) are adjusted when the platform altitude is varied.

[23] Our procedure for identification of sea surface samples proceeds as follows (in four steps). First, we remove the cloud-contaminated data by visual inspection of the ATM elevation and $R$ data. Those segments of the data that appear to be visibly smeared due to fog or low-level clouds are not included in our analysis. Admittedly, this is somewhat subjective but it serves to eliminate obvious cloud contaminated data segments. In addition, data collected during aircraft maneuvers (turns or changes in altitude) are not used. In the spring 2009 IceBridge acquisitions, atmospheric contamination was minimal (i.e., clear skies) and less than $2 \%$ of the data were discarded.

[24] Second, to select data samples suitable for use as sea surface references, the elevation distributions of consecutive $250 \mathrm{~m}$ ATM segments are examined and compared to the elevation distribution of the local $30 \mathrm{~km}$ segment $\left(h^{30 \mathrm{~km}}\right)$. The objective is to identify distinct low-elevation samples in these distributions. The $250 \mathrm{~m}$ segment length is chosen for ease of discrimination of small populations of sea surface samples (narrow leads) buried in the larger population of ice samples, and also to provide a large enough sample size $(\sim 10,000)$ to reduce noisiness in the elevation distributions used for detection of the peaks and valleys in these distributions. The mode and variability of the longer $30 \mathrm{~km}$ segments are used to provide measures of the elevation of the larger-scale ice-only surface. In this step, the multiple modes in each distribution (250 m segment) are identified based on the following conditions: a mode is considered significant if its size is greater than $10 \%$ of the size of the mode with the largest population $\left(M_{\max }\right)$, and greater than $5 \%$ of $M_{\max }$ above the adjacent minima (see Figure $3 \mathrm{e}$ ). From these multiple modes, we select the one with the lowest elevation and is more than one root-mean-square (1 RMS: root-mean-square deviation of the sample population below the mode, see Figure 3e) distance below the mode of $h^{30 \mathrm{~km}}$. If there is only one mode in a $250 \mathrm{~m}$ segment, the same comparison to $h^{30 \mathrm{~km}}$ is made as that segment may contain a large population of lead samples. This step ensures the elevation of the sea surface is significantly below

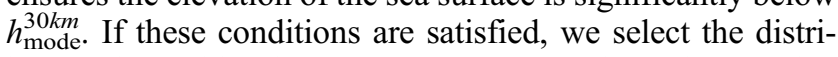
bution defined by this $250 \mathrm{~m}$ segment mode as the one that contains candidate sea surface samples.

[25] Third, we select candidate elevation samples in the neighborhood of the designated mode for use in estimating the mean sea surface. Those include samples in the elevation distribution below $h_{\text {cutoff }}$ (blue line in Figure $3 \mathrm{e}$ ), which is defined as the elevation that is the minimum of either its subsequent local minimum or the elevation at 1 RMS distance below the $30 \mathrm{~km}$ segment mode.

[26] Last, we require that the $R$ from these samples to be surfaces with low reflectivity with $R<0.25$ (i.e., $R_{\text {cutoff }}=$ $0.25)$. The value of $R_{\text {cutoff }}$ is based on examining the distributions of $R$ in the entire population (all four flights, a total of more than 2.96 million samples) of candidate low-elevation samples selected in the previous steps (see Figure 5). The distribution of low-elevation samples shows a bi-modal peak; we select the centroid of the lower mode to be the threshold $\left(R_{\text {cutoff }}\right)$. The trough between the modes is not selected because we would like a distribution of lowelevation samples with very low $R$ for estimating the sea surface. As a result of this process, approximately $0.5 \%$ of the ATM elevations from the 4 days were selected as sea surface references. Figures $3 \mathrm{e}$ and $4 \mathrm{e}$ show the $250 \mathrm{~m} R$ distributions (dashed black) as well as the $R$ distribution of the subset of elevation samples (dashed red) from the previous step (i.e., those samples $<h_{\text {cutoff }}$ ). The selected 
a) April 21, 2009

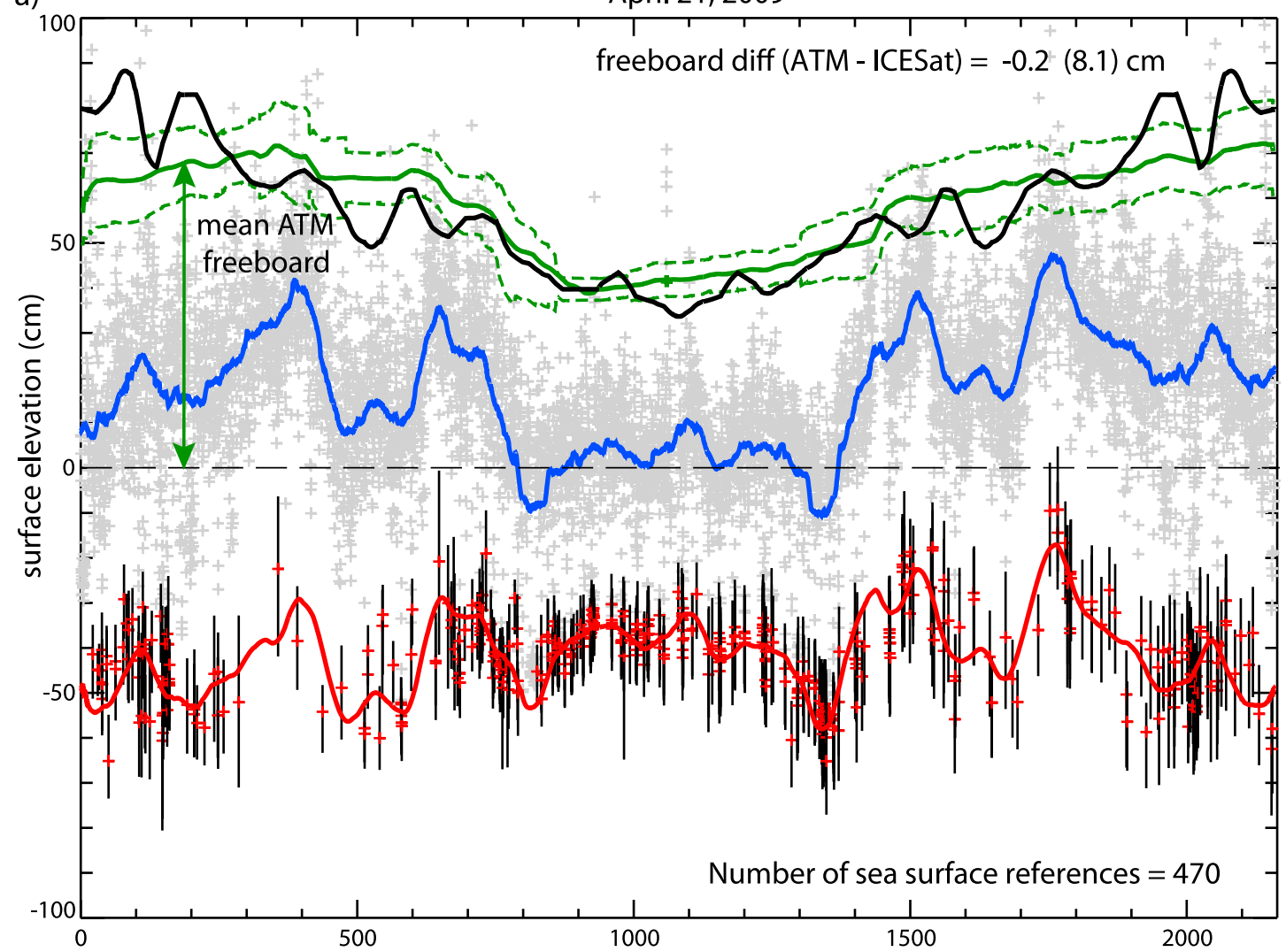

ATM Ice surface elevation ( $250 \mathrm{~m}$ mean)

Distance $(\mathrm{km})$

- ATM Ice surface elevation (50 km running mean)

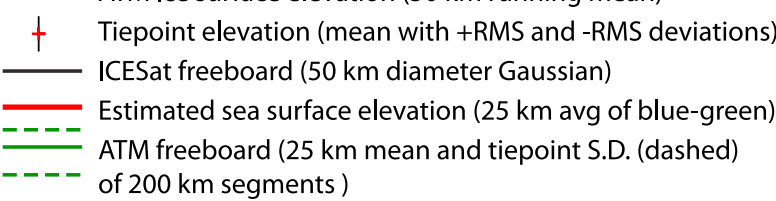

c)
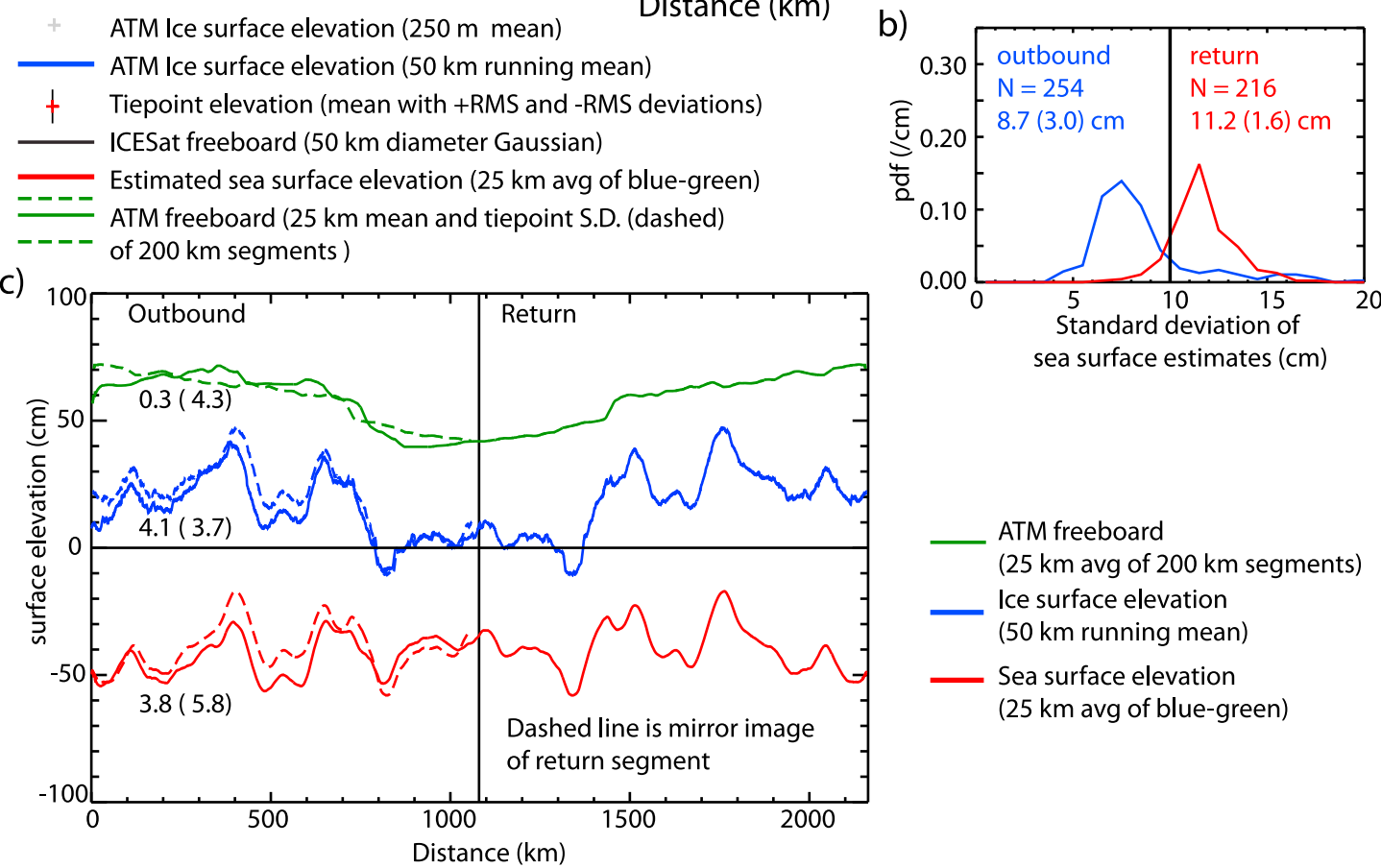

Figure 6. ATM lidar acquisitions from 21 April 2009. (a) Mean freeboard profile (green), surface elevation (blue), mean sea surface references (red crosses) with +RMS and - RMS deviations (black error bars), and sea surface elevation profile (red). Retrieved mean freeboards from ATM are compared with those from ICESat (black). (b) Variability of elevation of sea surface samples (standard deviation) in $250 \mathrm{~m}$ segments where sea surface samples are identified. (c) Comparison of the results from the outbound and return segments. The return flight is flown at a higher altitude. +RMS and -RMS are the root-meansquare deviations of the samples above and below the sample means. The length scales of averaging for individual profiles are shown in the legend. 




Figure 7. ATM lidar acquisitions from 31 March 2009. The description is the same as in Figure 6.

elevation samples, satisfying both the elevation and apparent reflectivity cutoffs, used to estimate the local sea surface are shown in Figures $3 \mathrm{~d}$ and $4 \mathrm{~d}$. In both examples, comparisons of the results with CAMBOT imagery show remarkably clean segmentations of the ATM data into ice and open water/thin ice. Between $10 \%$ and $40 \%$ of the ATM elevations in the four sample $250 \mathrm{~m}$ segments shown in Figures 3d and $4 \mathrm{~d}$ were selected for estimation of the elevation of the sea surface.

[27] Establishing the accurate height of the local open ocean surface is essential for determining freeboard and eventually ice thickness. As seen in Figures 3 and 4, open water in visible imagery appear dark compared to the ice and are easily identified. However, there can be a skim of thin newly frozen ice within the open areas that is sometimes not apparent in the visible imagery. So, there are potential biases due to the freeboard of thin ice in leads. However, since freeboard is only $\sim 10 \%$ of the ice thickness, the biases in terms of freeboard is relatively small. In any case, there will be unresolved centimeter-level biases in our estimates.

[28] The procedures described above provide estimates of sea surface elevation or tiepoints $\left(h_{\text {tiept }}\right)$ at $250 \mathrm{~m}$ segments where samples of open leads are identified. The elevation scatter in the selected sea surface samples within each segment, as we show later, is consistently 8 to $10 \mathrm{~cm}$ (see Figures $6 \mathrm{~b}, 7 \mathrm{~b}, 8 \mathrm{~b}$, and $9 \mathrm{~b}$ ). Thus, there is significant variability in these elevations due to noise in range determination as well as surface variability. The sensitivity to $R_{\text {cutoff }}$ is relativity small. For the 4 days examined here, varying the $R_{\text {cutoff }}$ between 0.225 and 0.275 changes the estimated sea surface by $\sim 1-2 \mathrm{~cm}$.

\subsection{Estimation of Sea Surface Height Profile}

[29] With the sea surface references (henceforth referred to as tiepoints) derived above, we can either: (1) compute the freeboard only in the vicinity of the tiepoints, or (2) using 


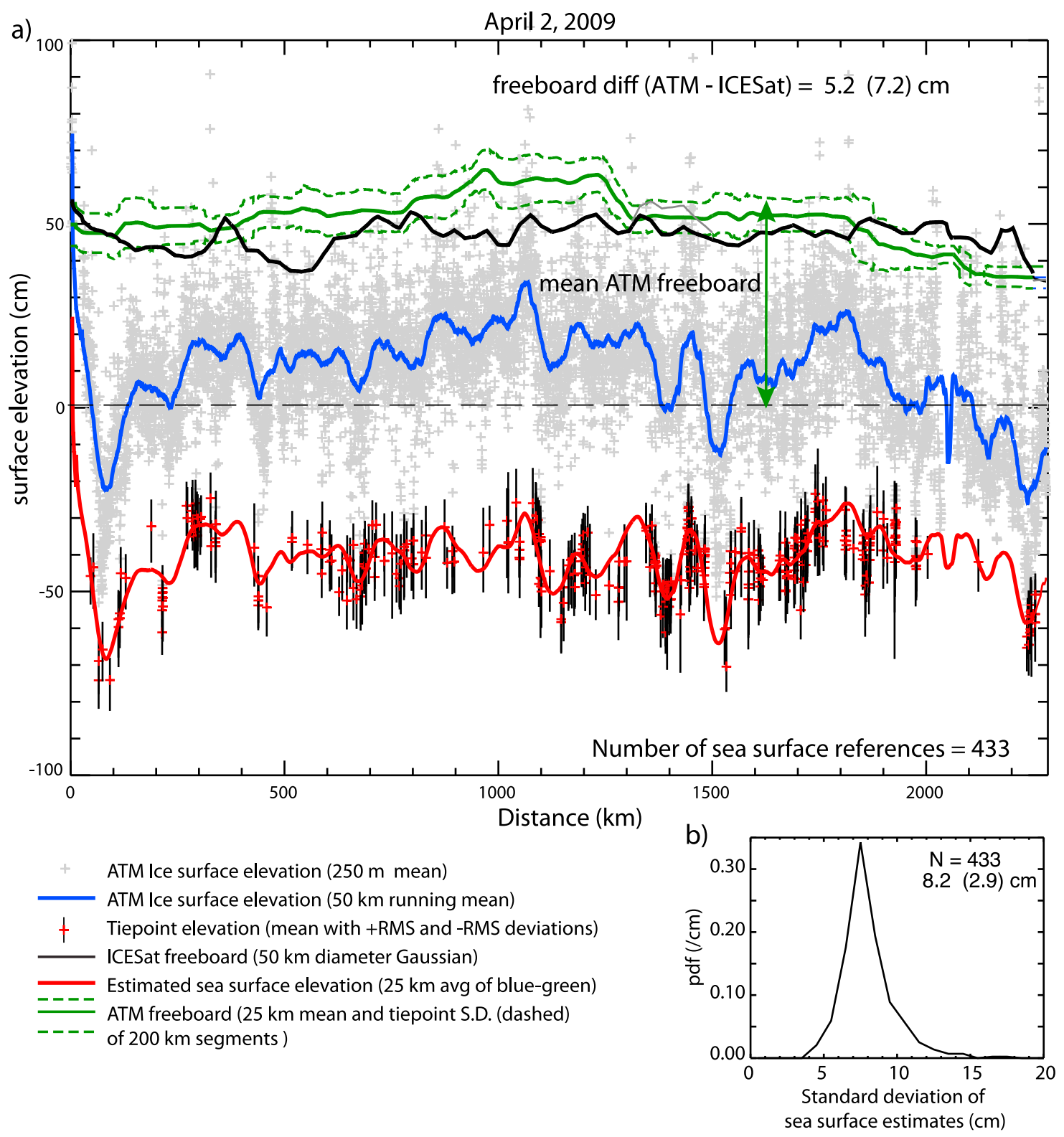

Figure 8. ATM lidar acquisitions from 2 April 2009. The description is the same as in Figure 6.

available tiepoints, construct the best along-track freeboard estimates with assumptions about the profile of the sea surface. With so few tiepoints available for each $\sim 2000 \mathrm{~km}$ track (only 470 on 21 April, 766 on 31 March, 433 on 2 April, and 306 on 5 April), we chose the latter approach to produce a near gap-free estimate of the sea surface profile. In this section, we describe our approach, followed by an example to illustrate this process in the next section.

[30] Our approach assumes that the $50 \mathrm{~km}$ running mean of the ATM elevation profile $\left(h_{A T M}^{50 \mathrm{~km}}(x)\right)$ to be a close replica of the residual sea surface $\left(\tilde{h}_{s s h}(x)\right)$ and thus a good initial estimate of its local sea surface profile. Given that, if we had an estimate of the mean freeboard locally $\left(\tilde{h}_{f}(x)\right)$, we can compute $\tilde{h}_{s s h}(x)$ viz:

$$
\tilde{h}_{s s h}(x)=h_{A T M}^{50 k m}(x)-\bar{h}_{f}(x) .
$$

[31] That is, $\tilde{h}_{s s h}(x)$ is the difference between $h_{A T M}^{50 \mathrm{~km}}(x)$ and the mean along-track freeboard, $\bar{h}_{f}(x)$, at some predetermined length scale. Why use the $50 \mathrm{~km}$ running mean of the surface elevation as an initial estimate of the sea surface profile? At this length scale, most of the small-scale elevation variability due to ridges and leads has been averaged out, and the remaining variations are due to slowly varying changes in mean freeboard and residuals in the sea surface. Certainly, this length scale has to be short enough to represent most of the variability in the sea surface but long enough that it is not affected by short-scale variability in freeboard. Admittedly, the selection of $50 \mathrm{~km}$ length scale is somewhat arbitrary but the results in later sections show that it is not an unreasonable choice. Furthermore, because of the changes in the spatial variability of the geoid and the mix of data that went into creating EGM2008, the 
a)

April 5, 2009

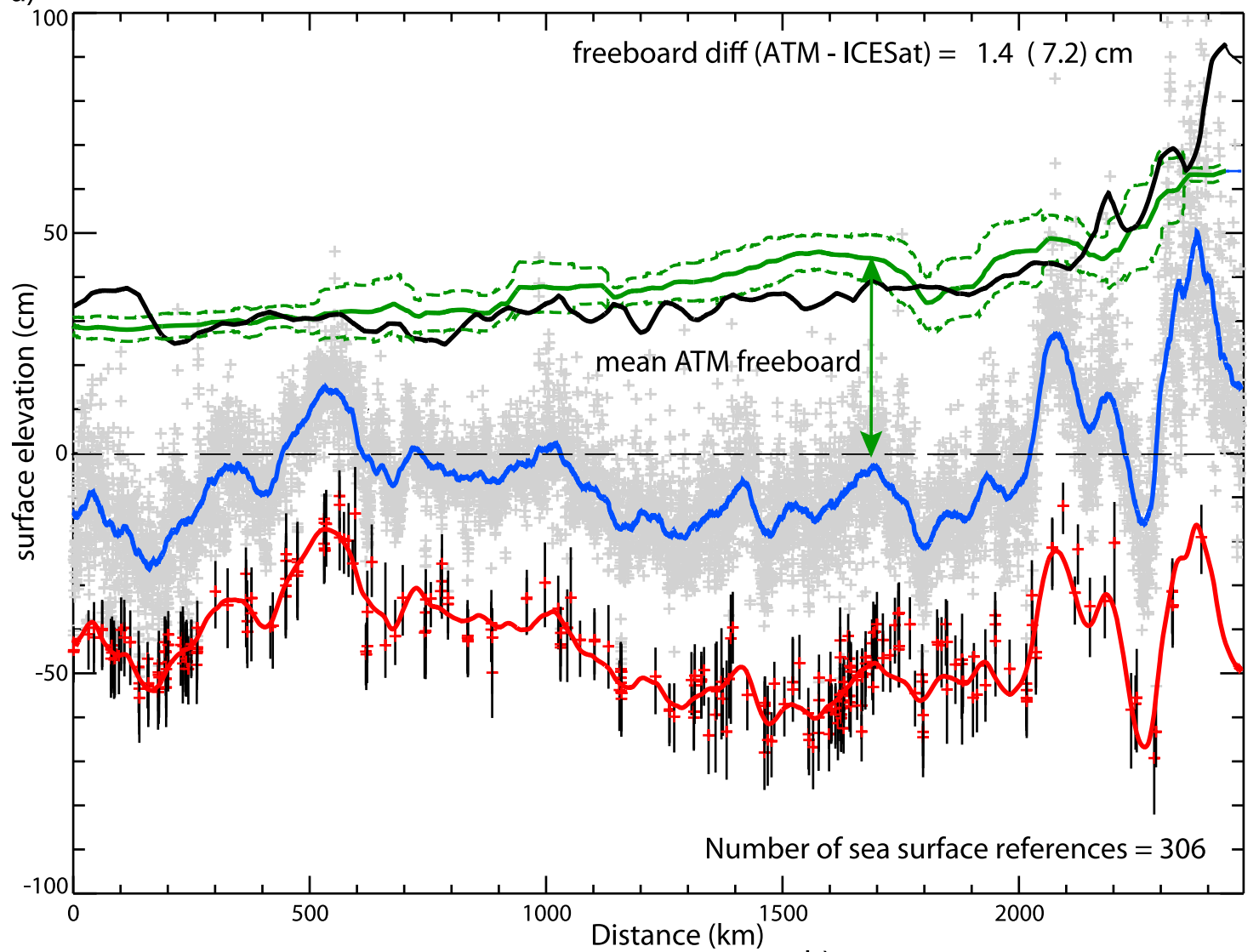

ATM Ice surface elevation ( $250 \mathrm{~m}$ mean)
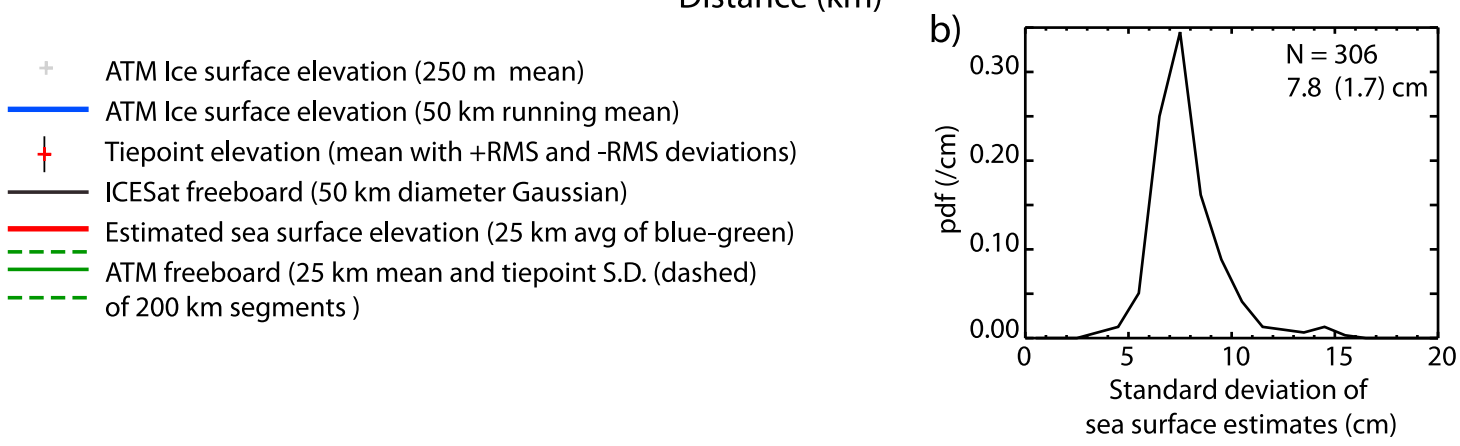

Figure 9. ATM lidar acquisitions from 5 April 2009. The description is the same as in Figure 6.

correlation length scale of the geoid residuals that is contained in the residual sea surface is not well defined. Thus, there may not be an optimal length scale for our purposes.

[32] How do we determine a length scale for the mean freeboard estimate $\bar{h}_{f}(x)$ ? This is based on practical considerations. Since our goal is to produce a near gap-free estimate of the sea surface profile, we select a length scale $(200 \mathrm{~km})$ such that there is always a usable number of tiepoint estimates along track for estimation of $\bar{h}_{f}(x)$. This is dependent on tiepoint density and the local separation of tiepoints along track. Here, an underlying assumption is that the residual sea surface $\tilde{h}_{s s h}(x)$ varies faster and with larger amplitude than the mean freeboard. It is inevitable under certain circumstances, that the freeboard and sea surface will vary at the same length scales locally. In those cases, the freeboard will be aliased into the local $(200 \mathrm{~km})$ residual sea surface profile.

[33] Given the above discussion, the mean freeboard, $\bar{h}_{f}(x)$, is estimated as the weighted mean of the difference between $h_{A T M}^{50 \mathrm{~km}}(x)$ and $h_{\text {tiept }}$ of available tiepoints $N_{t}$ over a $200 \mathrm{~km}$ segment centered at $x$,

$$
\bar{h}_{f}(x)=\frac{\sum_{i=1}^{N_{t}} \sqrt{N_{i}} \hat{h}_{f}\left(x_{i}\right)}{\sum_{i=1}^{N_{t}} \sqrt{N_{i}}}=\frac{\sum_{i=1}^{N_{t}} \sqrt{N_{i}}\left(h_{A T M}^{50 k m}\left(x_{i}\right)-h_{\text {tiept }}\left(x_{i}\right)\right)}{\sum_{i=1}^{N_{t}} \sqrt{N_{i}}}
$$

along $200 \mathrm{~km}$ segments. Here $h_{\text {tiept }}$ is the mean elevation of the available tiepoints from the $250 \mathrm{~m}$ ATM segments and $N_{i}$ is the number of elevation samples used in estimating each $h_{\text {tiept }}$. As a reminder, the known geoid undulations, ocean 
tides, inverted barometer effects and signal strength biases have been removed from all ATM elevations in our calculations. The estimate of $\bar{h}_{f}(x)$ is updated every $250 \mathrm{~m}$. The number of tiepoints $\left(N_{t}\right)$ along the $200 \mathrm{~km}$ segment constrains the allowed variability imposed by the noisy tiepoints. The standard deviation of freeboard, $\sigma_{h_{f}}$, within the $200 \mathrm{~km}$ segments, is a measure of the variability of the tiepoints that contributed to the overall estimate. Since the number of tiepoints varies along track, so do the quality of the $\tilde{h}_{s s h}(x)$ estimates. No estimates are provided when no tiepoints within $100 \mathrm{~km}$ are available. The following example demonstrates the efficacy of our approach. As a note, the short-scale variability or distribution of the actual freeboard near the resolution of the ATM footprints (if of interest) can be recovered after $\tilde{h}_{s s h}(x)$ is determined.

\subsection{An Example: 21 April}

[34] We use the ATM track from 21 April to illustrate the retrieval of $\bar{h}_{f}$ using available tiepoints $\left(h_{\text {tiept }}\right)$. This $\sim 1800 \mathrm{~km}$ flight track includes an outbound and a return segment that provided repeat coverage of the ice cover along a line that begins and terminates at Ellesmere Island (see Figure 1). Since these segments covered approximately the same sea ice (with a maximum separation of $8 \mathrm{~h}$ ) with nearly identical sea surface elevation (except for tidal variations), comparisons of the freeboard from the two segments should provide us with an assessment of: our assumptions; the robustness of our tiepoint selection procedure (described above); the repeatability of our freeboard retrievals; the efficacy of our sea surface estimation process; and, our understanding of the ATM data.

[35] The composite in Figure 6 shows the relevant data and results that illustrate the derivation of our freeboard estimates. Figure 6a shows the tiepoints, the estimated sea surface, the ATM elevations, the retrieved freeboard, and also ICESat freeboard along the same track. These are computed using equations (3) and (4). We first discuss the characteristics of the tiepoints and then the profiles of ice and sea surfaces, and freeboard.

\subsubsection{Variability of Tiepoint Elevations}

[36] Figure 6a shows the mean surface elevation of the 470 tiepoints (in red), together with their +RMS and - RMS deviations (black error bars) of the sample population. +RMS and -RMS are the root-mean-square deviations of the samples above and below the sample mean; they provide a measure of the asymmetry of the sample distribution around the mean. As a clarification, this is different from the expected variability of the estimated mean elevation, which is the standard deviation of the sample population divided by $\sqrt{ } N$, where $N$ is the number of samples used to determine the mean.

[37] The density of and distance between tiepoints along the track are highly variable. On this day, the tiepoint densities are greatest near Ellesmere Island and in the thinner ice where the platform approaches the turnaround point west of Banks Island. The tiepoint density (near $300 \mathrm{~km}$ to $500 \mathrm{~km}$ ) is lower in the early part of the track and higher on the return segment due to new openings in that part of the ice cover. A distinctly bimodal distribution is seen in the variability of the ATM samples contributing to tiepoint elevations - defined as the standard deviation of the sample population within each $250 \mathrm{~m}$ segment (see Figure $6 \mathrm{~b}$ ). The variability of the outbound tiepoints (mean $\sim 9 \mathrm{~cm}$ ) is lower than those in the return segment $(\sim 12 \mathrm{~cm})$. These differences are due to the higher flight altitude of the return segment (at $\sim 760 \mathrm{~m}$ ) compared to that of the outbound segment (nominal altitude of $\sim 460 \mathrm{~m}$ ). This increase in altitude weakens the apparent reflectivity in the ATM returns by a factor of 1.3 (from an average of 0.50 to 0.38 ), and reduces the signal-to-noise ratio (or increases the expected variability in the low-reflectance surfaces). To compensate for these changes, we adjusted $R_{\text {cutoff }}$ in our sea surface detection scheme (discussed in section 3.2) by the same factor (from 0.25 to 0.19 ). Notably, the variability of the selected tiepoint samples, approximately $8 \mathrm{~cm}$, is remarkably consistent for all the flights (see Figures $6 \mathrm{~b}, 7 \mathrm{~b}, 8 \mathrm{~b}$, and $9 \mathrm{~b}$ ) when the ATM lidar is operated at its nominal altitude.

\subsubsection{Sea Ice, Sea Surface, and Freeboard Profiles}

[38] In Figure 6a, we show the calibrated ATM elevations as individual samples of $250 \mathrm{~m}$ segment means (gray crosses) and as a profile of its $50 \mathrm{~km}$ running mean, $h_{A T M}^{50 \mathrm{~km}}$ (blue). The freeboard profile $\left(\bar{h}_{f}\right.$, green) is computed using equation (4). The variability of the freeboard at the tiepoint locations (standard deviation), within a $200 \mathrm{~km}$ along track segment, is shown as dashed lines (green) around the mean profile. The number used in this calculation varies and depends on available tiepoints but at least two are required in the process. The sea surface profile $\tilde{h}_{s s h}$ (red) is the difference between the $h_{A T M}^{50 \mathrm{~km}}$ and $\bar{h}_{f}$ as shown in equation (3). Visual comparison of $\tilde{h}_{s s h}$ (red) and the tiepoint samples show the goodness of fit of the profile to the sample points. [39] We compare $h_{A T M}^{50 \mathrm{~km}}, \bar{h}_{f}$, and $\tilde{h}_{s S h}$ of the outbound and return segments to assess the consistency of the observed elevations, the retrieved freeboard, and sea surface estimates. Mirrored replicas of these profiles from the return segment are plotted (as dashed lines) together with the outbound profiles to show the consistency of the results (in Figure 6c). The agreement is encouraging. The mean (standard deviation) differences between the outbound and return segments are $0.3(4.3) \mathrm{cm}, 4.1(3.7) \mathrm{cm}$, and $3.8(5.8) \mathrm{cm}$ for $\bar{h}_{f}, h_{A T M}^{50 \mathrm{~km}}$, and $\tilde{h}_{s s h}$, respectively. The results show that our estimates of the freeboard profile are repeatable to within $\sim 4 \mathrm{~cm}$ but dependent locally on the density of sea surface references. Variability of the ice cover due to ice motion, which presumably dominates, gives rise to differences in the actual freeboard observed. Another source of variability is the time-varying sea surface between observations. In our case, the consistent changes in ice surface and the sea surface during the return track led to a small overall change in the sea ice freeboard.

[40] To illustrate the effect of the elevation adjustments previously described, we compute the changes in the freeboard of the 21 April flight due to the calibration (in section 3.1) and to the changes in apparent reflectivity (in section 3.4.1) from a higher platform altitude. The calibration adjustment decreases the range and consequently the freeboard by an average of $1.75 \mathrm{~cm}$. The shift in $R_{\text {cutoff }}$ from 0.25 to 0.19 results in a higher freeboard of $2.5 \mathrm{~cm}$, due to the filtering of brighter samples with higher elevations.

[41] Based on the results here, it is interesting to note that the available tiepoints still seem effective in the estimation of the mean freeboard even when the density of tiepoints is relatively low in certain parts of the segment. 


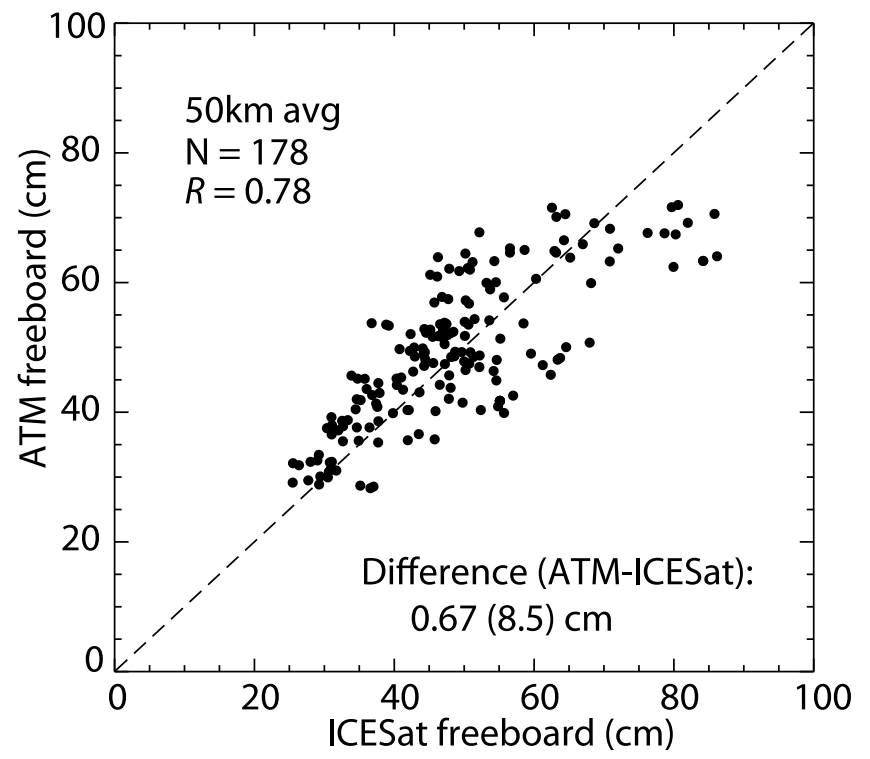

Figure 10. Comparison of ATM and ICESat derived freeboards from the four transects (50 km averages).

\subsubsection{Comparison With ICESat Freeboard}

[42] Here, we compare the ATM freeboard estimates with those obtained from ICESat (see Figure 6a). In 2009, the ICESat lidar was operated between 9 March through 11 April and the OIB flights overlapped with the latter part of this period. Even though some of the OIB flight segments were designed to fly along ICESat tracks for comparison purposes, ICESat freeboard estimates are not always available due to cloudiness and retrievals tend to be rather sparse along a specific ground track. In our analysis, we extract ICESat freeboards from the gridded monthly composite, which represents available freeboards smoothed with a $50 \mathrm{~km}$-diameter Gaussian kernel. Thus, we note that this is not a point-to-point comparison as there are expected differences due to spatial and temporal variability caused by misregistrations in space and time. Nevertheless, we do expect similarity in the large-scale mean and gradients in freeboard over the Arctic Basin to be reproduced. Indeed, the results show this to be the case in all our comparisons (see Figures 6, 7, 8 and 9). The overall difference between the ATM and ICESat freeboards are $0.7(8.5) \mathrm{cm}$ (see Figure 10). In this particular case (21 April), the freeboard is higher near the Ellesmere coast $(\sim 80 \mathrm{~cm})$ and is lower farther out into the southern Beaufort Sea $(\sim 40 \mathrm{~cm})$. The undulations in the ICESat freeboard are, however, not reproduced. But these may be a result of residual geoid signals in the ICESat estimates because we do not expect the sea ice freeboard to display such undulations. We will return to this discussion of some of these issues in the conclusion.

\section{Results}

[43] In this section, we discuss the freeboard estimates of the individual flights, their overall comparisons with ICESat, and summarize their freeboard distributions over first year and multiyear ice. We comment briefly (similar to that provided in section 3.4 for 21 April) on the profiles of freeboard, ATM elevation, and sea surface from the remaining three flights (flown on 31 March, 2 April, and 5 April). The results are summarized in Figures 7, 8, and 9. Remarks about the residual sea surface heights seen in our estimates are also discussed.

\subsection{Profiles of Freeboard, ATM Elevation, and Sea Surface: 31 March}

[44] This flightline acquired data over the thick ice of the Lincoln Sea, the sea ice north of the margins of Greenland, the Fram Strait, and the coast of Greenland (Figure 1). There are 766 tiepoints, with a mean variability of $7.9 \mathrm{~cm}$ less than that observed in the 21 April tiepoints (Figure 6), since these tiepoints include those extracted from a higher platform altitude. There are more available tiepoints in this flight because of the large openings in the ice cover associated with gradients in ice motion close to the coast. All the other flights have less than 500 tiepoints. The freeboard starts off near $70 \mathrm{~cm}$ in the Lincoln Sea and then levels off, starting around $200 \mathrm{~km}$ into the flight track, to $\sim 40-50 \mathrm{~cm}$ throughout most of flight. The ATM freeboard in the latter part of the flight is consistently higher likely because of high-resolution sampling of the thicker sea ice close to the coast, compared to the large-scale averages from ICESat. The overall difference between the ATM and ICESat freeboards is $-3.5(9.7) \mathrm{cm}$. Similarly, there are undulations in the ICESat freeboard, discussed earlier, that are not reproduced. Again, this may be a result of residual geoid signals in the ICESat estimates.

\subsection{Profiles of Freeboard, ATM Elevation, and Sea Surface: 2 April}

[45] The southern endpoint of this track is just north of the MacKenzie Delta (see Figure 1). The acquisitions are from a mix of seasonal and older ice near the edge of the MYI pack west of the Canadian Arctic Archipelago. The northern part of the track terminates just south of $86^{\circ} \mathrm{N}$ before it enters the thick MYI cover of the Lincoln Sea. There are 433 tiepoints, with a mean variability of $8.2 \mathrm{~cm}$ (Figure 8) consistent with values seen on 31 March. The average freeboard over most of the ice cover is between 50 and $60 \mathrm{~cm}$, with it slightly thicker over the center portion of the flight where there is a high concentration of MYI. The overall difference between the ATM and ICESat freeboards is $5.2(7.2) \mathrm{cm}$. Similarly, there are undulations in the ICESat freeboard, discussed earlier, that are not reproduced. Again, this may be a result of residual geoid signals in the ICESat estimates.

\subsection{Profiles of Freeboard, ATM Elevation, and Sea Surface: 5 April}

[46] This trans-Arctic survey originated east of Barrow and covered the large expanse of the seasonal ice in the Beaufort Sea and the Canada Basin (Figure 1). The flight also acquired data over the thick MYI cover just north of the Greenland coast prior to landing in Thule. This flight provided the best along-track profile for examining the gradient in Arctic freeboard in the regional transition from a purely seasonal to MYI cover. There are 306 available tiepoints, with a mean variability of $7.8 \mathrm{~cm}$ (Figure 9) that is consistent with values from the other days. The average freeboard varies between 30 and $40 \mathrm{~cm}$ in the predominantly seasonal ice region and increases to $60 \mathrm{~cm}$ near the Greenland coast. The overall difference between the ATM and 


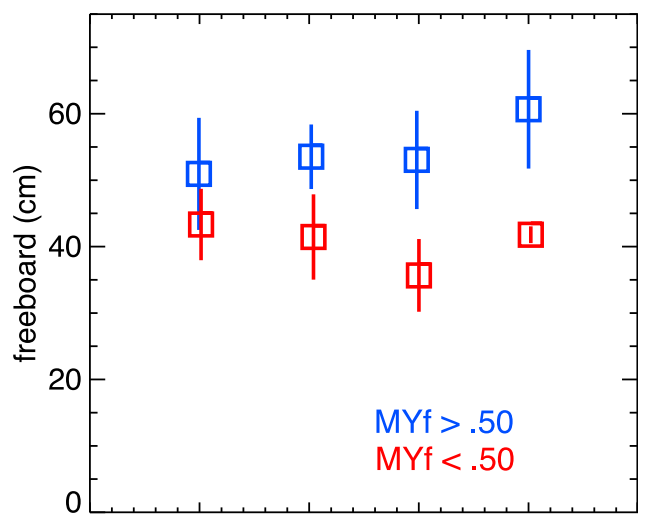

Mar-31 Apr-02 Apr-05 Apr-21

Figure 11. Freeboards of first year and multiyear sea ice along the four tracks. (Squares and error bars are means and standard deviations, respectively).

ICESat freeboards is $1.4(7.2) \mathrm{cm}$. The larger difference in freeboard near the end of the flight segment is likely due to the low density of tiepoints and the large sea surface variability (nearly $0.5 \mathrm{~m}$ ) within a distance of less than $200 \mathrm{~km}$ from the end of the track. The characteristic freeboard undulations in the ICESat freeboard are somewhat less pronounced as in the other days.

\subsection{Comparison With ICESat: A Summary}

[47] The scatterplot in Figure 10 compares the ATM freeboard estimates from the four OIB flights in 2009 with those from ICESat. Samples on the plot represent $50 \mathrm{~km}$ averages. Overall difference between the ATM and ICESat freeboards (ATM minus ICESat) is $0.7(8.5) \mathrm{cm}$, with a correlation of 0.78 between the data sets of one hundred seventy-eight $50 \mathrm{~km}$ samples. The agreement seems quite remarkable given the potential sources of uncertainties. It is important to note, however, that we have only demonstrated the capability to retrieve freeboard consistently from both instruments. Absolute measures of freeboard uncertainties and the relative contribution of each instrument to these differences are more difficult to ascertain. Kwok et al. [2007] estimated their retrieval procedures could provide consistent freeboard estimates, along $25 \mathrm{~km}$ ICESat segments, with uncertainties of better than $7 \mathrm{~cm}$. At $50 \mathrm{~km}$, this would be $\sim 5 \mathrm{~cm}$ (i.e., $7 / \sqrt{2} \mathrm{~cm}$ ). If we assume this to be the contribution of ICESat, then the contribution of the freeboard retrieval procedure described herein would be $\sim 6.9 \mathrm{~cm}$; thus, somewhat higher than those retrievals from ICESat. As we can see here, the freeboard estimates are highly dependent on the retrieval approach.

\subsection{Freeboard Over First Year and Multiyear Ice}

[48] For the four flights, the lowest mean ice freeboard $(28 \mathrm{~cm})$ is seen in 5 April where the flight track sampled the large expanse of seasonal ice in the western Arctic. The highest mean freeboard $(71 \mathrm{~cm})$ is seen in the MYI just west of Ellesmere Island from 21 April. Here, we compare the first year and MYI freeboard (see Figure 11) from the 4 days. To determine the ice-type membership of individual freeboard samples, we used the MYI concentrations from QuikSCAT. A freeboard estimate is classified based on its location on the MYI map (gridded $12.5 \mathrm{~km}$ estimates): when a sample is located within a gridded cell with $\geq 50 \%$ MYI, it is categorized as MYI; samples in cells with $\leq 50 \%$ MYI are assigned to the FY ice category. The expected contrast in freeboard between the two ice types (i.e., MYI > first year ice freeboard) is seen in all flights. The mean freeboards are $41 \mathrm{~cm}$ and $55 \mathrm{~cm}$ over first year and MYI, respectively.

\subsection{Unmodeled Sea Surface Height}

[49] There are variations in the unmodeled sea surface of up to $0.5 \mathrm{~m}$, frequently at very short length scales (see Figures 6, 7, 8 and 9). For instance, we see large changes in the residual sea surface of over $30 \mathrm{~cm}$ within a short distance of $\sim 100 \mathrm{~km}$ (or $3 \mathrm{~cm} / 10 \mathrm{~km}$ ) at around $450 \mathrm{~km}$ and $800 \mathrm{~km}$ into the track on April 21 (see Figure 6). These short-scale variations are due to residual undulations in the geoid. It is unlikely that ocean tides or dynamic topography would contribute significantly to this magnitude of variability at these short length scales. Some of the small undulations seen in the ICESat freeboard (discussed in section 3.4.3) may also be residuals and artifacts due to the unmodeled geoid. Thus, the broader implication is that there are significant residuals in the EGM2008 geoid and that one could incur significant error if a sea surface reference available at one location is used to compute freeboard some distance away from that reference without some assumptions about the sea surface. That distance from the reference, however, is dependent on the retrieval algorithm. In our procedure discussed here, our shorter-scale sea surface $(50 \mathrm{~km})$ derived directly from the ATM data seems to work reasonably well.

\section{Conclusions}

[50] We note that calibration of the elevation data is an important step prior to the use of the ATM elevations for freeboard determination, particularly when surfaces of low reflectance (open water and thin ice) are used to estimate sea surface elevation. This is due to expected biases in the determination of lidar range when the apparent reflectivity is low. The freeboard profiles are repeatable to within $\sim 4 \mathrm{~cm}$ but are dependent locally on the density of sea surface references.

[51] In our sea surface determination procedure, the apparent reflectivity is used as an indicator of open water/ thin ice surfaces. The lidar configuration on the P-3 platform in 2009 provides consistent and stable apparent reflectivity that proved to be extremely valuable for separation of the high-reflectance ice surfaces from the lower-reflectance openings in the ice cover. Furthermore, the 2009 IceBridge data set was exceptionally cloud-free and less than $2 \%$ of the acquisitions were discarded due to cloud contamination. This contributed to the relative ease in the identification of sea surface tiepoints. As part of the ATM system, a simple camera, not intended to produce cartographic quality imagery, provided a useful record for visual inspection of the surfaces sampled. In subsequent IceBridge campaigns, an airborne digital camera (Digital Mapping System (DMS)) acquires high-resolution (submeter) panchromatic imagery for the purpose of integrated ATM-DMS analysis for identification of low-reflectance sea surface references. This will add to the quality of the sea surface estimates.

[52] We construct the best along-track freeboard estimates using our tiepoints together with assumptions about 
the profile of the sea surface. Our assumption is that the difference between the $50 \mathrm{~km}$ running mean of the ATM elevation profile and averaged total freeboard to be a good representation of the residual sea surface elevation. The results showed that this assumption seems to be effective. Overall difference between the ATM and ICESat freeboards is $0.7(8.5) \mathrm{cm}$, with a correlation of 0.78 between the data sets of one hundred seventy-eight $50 \mathrm{~km}$ averages. ICESat freeboards are from the procedures described by Kwok et al. [2007] and Kwok and Cunningham [2008]. We have demonstrated the capability to retrieve freeboard consistently from both instruments and the agreement is quite remarkable given the potential sources of uncertainties. The expected contrast in freeboard between the two ice types (i.e., MYI > first year ice freeboard) is seen in all flights. From the four flights, the lowest mean ice freeboard $(28 \mathrm{~cm})$ is seen in 5 April where the flight track sampled the large expanse of seasonal ice in the western Arctic. The highest mean freeboard $(71 \mathrm{~cm})$ is seen in the multiyear ice just west of Ellesmere Island from 21 April.

[53] Also noteworthy are the unmodeled variations in the sea surface of up to $0.5 \mathrm{~m}$, frequently at very short length scales that are due to residual undulations in the geoid. Thus, the broader implication is that there are significant residuals in the EGM2008 geoid and that one could incur significant error if a sea surface reference available at one location is used to compute freeboard some distance away from that reference without some assumptions about the sea surface. That distance from the reference, however, is dependent on the retrieval algorithm. In our procedure discussed here, our shorter-scale sea surface is derived directly from the ATM data. Our experience here will be important for design of future procedures to obtain sea surface estimates as the residual variability of the sea surface is embedded in the surface elevation estimates.

[54] As a final remark, we have demonstrated the usefulness of ATM data and have established a level of confidence in quality and utility of the IceBridge data, i.e., using the ATM acquisitions as a bridge between IceBridge and ICESat. However, unlike satellite data, uncompensated aircraft motion (due to flying conditions) in addition to clouds affect the quality of airborne data sets; this necessitates careful and frequent inspections of the data stream. In 2009, the atmospheric conditions were exceptionally benign for data acquisition. The challenge as to how we can use ATM elevations, with limited coverage, to detect changes in freeboard and thickness of the Arctic sea ice cover remains.
[55] Acknowledgments. We thank Ron Lindsay and another reviewer for providing valuable comments that have contributed to improvements of our manuscript. The QuikSCAT data were provided by the Physical Oceanography DAAC at the Jet Propulsion Laboratory, Pasadena, California. The IceBridge data were provided by the National Snow and Ice Data Center. RK and GFC carried out this work at the Jet Propulsion Laboratory, California Institute of Technology, under contract with the National Aeronautics and Space Administration.

\section{References}

Connor, L. N., S. W. Laxon, A. L. Ridout, W. B. Krabill, and D. C. McAdoo (2009), Comparison of Envisat radar and airborne laser altimeter measurements over Arctic sea ice, Remote Sens. Environ., 113, 563-570, doi:10.1016/j.rse.2008.10.015

Giles, K. A., S. W. Laxon, D. J. Wingham, D. W. Wallis, W. B. Krabill, C. J. Leuschen, D. McAdoo, S. S. Manizade, and R. K. Raney (2007), Combined airborne laser and radar altimeter measurements over the Fram strait in May 2002, Remote Sens. Environ., 111, 182-194, doi:10.1016/j. rse.2007.02.037.

Krabill, W., W. Abdalati, E. Frederick, S. Manizade, C. Martin, J. Sonntag, R. Swift, R. Thomas, C. Wright, and J. Yungel (2000), Greenland ice sheet: High-elevation balance and peripheral thinning, Science, 289, 428-430, doi:10.1126/science.289.5478.428.

Krabill, W. B., W. Abdalati, E. B. Frederick, S. S. Manizade, C. F. Martin, J. G. Sonntag, R. N. Swift, R. H. Thomas, and J. G. Yungel (2002), Aircraft laser altimetry measurement of elevation changes of the Greenland ice sheet: Technique and accuracy assessment, J. Geodyn., 34, 357-376, doi:10.1016/S0264-3707(02)00040-6.

Krabill, W., et al. (2004), Greenland ice sheet: Increased coastal thinning, Geophys. Res. Lett., 31, L24402, doi:10.1029/2004GL021533.

Kurtz, N. T., T. Markus, D. J. Cavalieri, W. B. Krabill, J. G. Sonntag, and J. Miller (2008), Comparison of ICESat data with airborne laser altimeter measurements over Arctic sea ice, IEEE Trans. Geosci. Remote Sens., 46, 1913-1924, doi:10.1109/TGRS.2008.916639.

Kwok, R. (2004), Annual cycles of multiyear sea ice coverage of the Arctic Ocean: 1999-2003, J. Geophys. Res., 109, C11004, doi:10.1029/ 2003JC002238.

Kwok, R. (2011), Satellite remote sensing of sea-ice thickness and kinematics: A review, J. Glaciol., 56, 1129-1140, doi:10.3189/002214311796406167.

Kwok, R., and G. F. Cunningham (2008), ICESat over Arctic sea ice: Estimation of snow depth and ice thickness, J. Geophys. Res., 113, C08010, doi:10.1029/2008JC004753.

Kwok, R., G. F. Cunningham, H. J. Zwally, and D. Yi (2007), Ice, Cloud, and land Elevation Satellite (ICESat) over Arctic sea ice: Retrieval of freeboard, J. Geophys. Res., 112, C12013, doi:10.1029/2006JC003978.

Kwok, R., G. F. Cunningham, M. Wensnahan, I. Rigor, H. J. Zwally, and D. Yi (2009), Thinning and volume loss of Arctic Ocean sea ice cover: 2003-2008, J. Geophys. Res., 114, C07005, doi:10.1029/2009JC005312.

G. F. Cunningham and R. Kwok, Jet Propulsion Laboratory, California Institute of Technology, 4800 Oak Grove Dr., Pasadena, CA 91109, USA. (ron.kwok@jpl.nasa.gov)

W. B. Krabill, Laboratory for Hydrospheric Processes, NASA Goddard Space Flight Center, Wallops Island, VA 23337, USA

S. S. Manizade, URS Corporation, NASA Wallops Flight Facility, Wallops Island, VA 23337, USA. 